\title{
Carbon nanotube reinforced hybrid composites: Computational modeling of environmental fatigue and usability for wind blades
}

Dai, Gaoming; Mishnaevsky, Leon

Published in:

Composites Part B: Engineering

Link to article, DOI:

10.1016/j.compositesb.2015.03.073

Publication date:

2015

Document Version

Peer reviewed version

Link back to DTU Orbit

Citation (APA):

Dai, G., \& Mishnaevsky, L. (2015). Carbon nanotube reinforced hybrid composites: Computational modeling of environmental fatigue and usability for wind blades. Composites Part B: Engineering, 78, 349-360.

https://doi.org/10.1016/j.compositesb.2015.03.073

\section{General rights}

Copyright and moral rights for the publications made accessible in the public portal are retained by the authors and/or other copyright owners and it is a condition of accessing publications that users recognise and abide by the legal requirements associated with these rights.

- Users may download and print one copy of any publication from the public portal for the purpose of private study or research.

- You may not further distribute the material or use it for any profit-making activity or commercial gain

- You may freely distribute the URL identifying the publication in the public portal 


\title{
CARBONE NANOTUBE REINFORCED HYBRID COMPOSITES: Computational modelling of environmental fatigue and their usability for wind blades
}

\author{
Gaoming Dai* and Leon Mishnaevsky Jr.* \\ Department of Wind Energy, Technical University of Denmark, Roskilde, Denmark \\ E-mail: ggda@dtu.dk, lemi@dtu.dk
}

\begin{abstract}
:
The potential of advanced carbon/glass hybrid reinforced composites with secondary carbon nanotube reinforcement for wind energy applications is investigated here with the use of computational experiments. Fatigue behavior of hybrid as well as glass and carbon fiber reinforced composites with and without secondary CNT reinforcement is simulated using multiscale 3D unit cells. The materials behavior under both mechanical cyclic loading and combined mechanical and environmental loading (with phase properties degraded due to the moisture effects) is studied. The multiscale unit cells are generated automatically using the Python based code. 3D computational studies of environment and fatigue analyses of multiscale composites with secondary nano-scale reinforcement in different material phases and different CNTs arrangements are carried out systematically in this paper. It was demonstrated that composites with the secondary CNT reinforcements (especially, aligned tubes) present superior fatigue performances than those without reinforcements, also under combined environmental and cyclic mechanical loading. This effect is stronger for carbon composites, than for hybrid and glass composites.
\end{abstract}

Keywords: A: Nano composites; A: Carbon nanotubes; B: Fatigue, B: Interfacial strength, C: Finite element analysis (FEA)

\section{Introduction}

The future perspectives of wind energy utilization depend on the development and reliability of extra-large off-shore wind turbines [1]. Wind turbines are subject to long term cyclic mechanical and environmental loading, involving complex off-axis tensile, compressive and shear loading. The creation of such wind turbines requires the development of new, strong, fatigue resistant materials, which can sustain cyclic, random mechanical, thermal and environmental loadings over years keeping their high stiffness and integrity.

A number of experimental and computational studies have been carried out to develop better materials for wind turbines [1-7]. Among various ideas to enhance the performances of the 
composite materials for wind energy applications, two approaches attract a growing interest of research community and industry: hybrid composites and nanoreinforced composites.

Hybrid composites (e.g., mixed carbon and glass fibers) allow to combine the advantages of both groups of fibers (for the case of carbon/glass composites, low price of glass fibers, low weight and high tensile strength and stiffness of carbon fibers) and compensate their weaknesses (again, high costs and low compressive strength of carbon fibers) [4-17]. So, Ong and Tsai [4] demonstrated that the full replacement of cheap and easily available glass fibers by very stiff, strong and lightweight carbon fibers for a $8 \mathrm{~m}$ wind turbine blades leads to $80 \%$ weight savings, and cost increase by $150 \%$, while a partial $(30 \%)$ replacement would lead to only $90 \%$ cost increase and $50 \%$ weight reduction. In a number of works, the strength and damage mechanisms of hybrid composites were studied It was reported, among others, that the incorporation of glass fibers in carbon fiber reinforced composites allows the improvement of their impact properties and tensile strain to failure of the composite. Manders and Bader [11] observed an enhancement of the failure strain of the carbon fiber reinforced phase when "carbon fiber is combined with less-stiff higher-elongation glass fiber in a hybrid composite".

Another approach to improve the composite performances (additionally to and keeping in place the advantages of both strong fibers and polymer matrix) is nanoreinforcing the matrix. It has been observed in many studies that the addition of small amount of nanoparticles (e.g. graphene, carbon nanotubes, or silicates and clay particles with high aspect ratios) to fiber reinforced composites can be used to improve composite properties [18-29]. According to [18], matrix-dominated properties (flexural and interlaminar shear strength) are drastically improved by the CNT additions to fiber-reinforced thermoplastic composites, while fiber-controlled properties (such as tensile strength and stiffness) are improved only slightly. In [19-21], the authors compared the composites with CNTs dispersed in matrix and distributed in fiber sizing. They observed that the crack initiation toughness increases (by $10 \%$ if CNTs in sizing and by $25 \%$ if in matrix) and the crack propagation toughness decreases (by 30...50\%) when CNTs are placed in sizing [20]. However, in the system with carbon fibers, both crack initiation and propagation energies were improved by CNT addition in matrix [21], what is related with CNT bridging and other toughening mechanisms (crack deflection, blocking). In [22], it was shown that the tensile strength of glass fibers increases significantly with increasing CNT content. $45 \%$ increase in shear strength is achieved by adding $0.015 \mathrm{wt} \%$ nanotubes into glass fiber reinforced vinyl ester composite [23]. 30\% enhancement of the interlaminar shear strength was achieved by deposition of multi and single walled CNT on woven carbon fabric fibers in epoxy matrix [26, 27]. Interlaminar toughness and strength of alumina fiber reinforced plastic laminates were improved by $76 \%$ and $9 \%$ due to the radially aligned CNTs in both interlaminar and intra-laminar regions [28]. Thus, the secondary nanoreinforcement (e.g., carbon nanotubes or nanoclay distributed in polymer matrix or fiber sizing) have positive effect on the shear and compressive strength, fracture toughness and fatigue resistance of composites.

However, the question arises whether and to which degree this potential of material improvement is useful and usable for wind turbine blades, i.e. structures to be used under 
conditions of combined mechanical and environmental loading, high humidity, off-axis, complex loadings. A series of computational studies is carried out here in order to clarify the potential of these material modifications for wind blade materials. Using the numerical experiments, we seek to investigate how and whether the effects of hybrid and nanoreinforced structures of polymer composites (both each of them and combined) are beneficial for the fatigue resistance and service properties of the composites to be used in the wind turbine conditions. To do this, we use the computational micromechanics approach, based on multiscale and multi-element unit cell models [8, 29], developed and tested in [29]. Collecting the literature data on the local materials properties and humidity effect on the properties of different phases, we introduce these data into the 3D multiscale computational models of composites and evaluate and compare the output materials performances. Carrying out computational experiments (numerical testing) of various composite structures, we explore the structure-mechanical properties relationships and can develop recommendations toward the improvement of the materials properties.

\section{Computational model: Generation, Simulation, Material properties}

\section{1. $\quad 3 D$ Hierarchical computational model: Python based model generation}

Due to the large difference of the dimension scale of the fiber reinforced composite (macroscale) and CNTs reinforcement (nano-scale), we use here the concept of macro-micro multiplestep modeling [29], to simulate the damage evolution in the material.

In order to carry our systematic computational studies of the microstructure-strength relationships of hybrid composites with secondary CNT reinforcements, a number of 3D computational models reflecting the hybrid composite structures should be generated. For this, a special Python based software code for the automatic generation of unit cells with multiple cylinder-like reinforcements [29-34] was generalized and improved. The newly developed code allows to generate hierarchical FE models with pre-defined structures, including the macroscale unit cell (with hybrid unidirectional/misaligned fibers and variable fiber content) and lower scale unit cell model (with aligned/random oriented carbon nanotubes, surrounded by the effective interface layers, see [37, 38]), automatically. Examples of the models are shown in Fig. 1(a). For comparison, we show a micrograph of a carbon fiber with CNTs, reprinted from [39] (Fig. 1b)

\subsection{Micro-scale unit cell generation with multiple high aspect ratio CNTs: Algorithm of cylinder distribution}

For the generation of lower scale unit cell models with many high aspect ratio carbon nanotubes, the following approach has been used. The carbon nanotubes were presented as cylinders. The reinforcing CNTs are randomly distributed in the fiber-matrix interface and (in some models) randomly oriented. To take into account the interface effect, the generalized effective interface layer concept was used [30-38]. 
In order to distribute the high aspect ratio CNT cylinders in the microscope unit cell, the following algorithm was used. The condition that the CNTs do not overlap is written as follows:

$$
\begin{aligned}
& d_{f-f} \geq 2 R_{f} \\
& d_{C N T-C N T} \geq 2 r_{C N T} \\
& d_{f-C N T} \geq R_{f}+r_{C N T}
\end{aligned}
$$

where, $d_{f-f}, d_{C N T-C N T}, d_{f-C N T}$ are distances between closest fibers, closest CNTs and a fiber and $\mathrm{CNT}$, respectively, $R_{f}$ - radius of fiber, $r_{C N T}$ - radius of carbon nanotube. When generating the unit cell with multiple randomly oriented CNTs, the program places each new CNT into the cell one after another, using random number generator to get the new CNT location and checking that the reinforcements don't overlap. For this, the distance between straight lines (CNT cylinder axes) located in different planes was calculated using the spatial vector projection theory. We take $P_{1}\left(x_{1}, y_{1}, z_{1}\right)$ and $P_{2}\left(x_{2}, y_{2}, z_{2}\right)$ as two points on the central line of new CNT cylinder (the line is marked as $\left.L_{1}\right)$ and $P_{3}\left(x_{3}, y_{3}, z_{3}\right)$ and $P_{4}\left(x_{4}, y_{4}, z_{4}\right)$ as two points on the central line of one of the existing CNT cylinders (marked as $L_{2}$ ). From the analytic geometry, the direction vector of $l_{1}$ and $l_{2}$ are described as

$$
\begin{aligned}
& \overline{L_{1}}=\left(x_{2}-x_{1}, y_{2}-y_{1}, z_{2}-z_{1}\right) \\
& \overline{L_{2}}=\left(x_{4}-x_{3}, y_{4}-y_{3}, z_{4}-z_{3}\right)
\end{aligned}
$$

The vector of common perpendicular (marked as $l$ ) of the two lines is given by:

$$
\begin{aligned}
\vec{L} & =\overrightarrow{L_{1}} \times \overrightarrow{L_{2}} \\
& =\left|\begin{array}{ccc}
i & j & k \\
x_{2}-x_{1} & y_{2}-y_{1} & z_{2}-z_{1} \\
x_{4}-x_{3} & y_{4}-y_{3} & z_{4}-z_{3}
\end{array}\right|
\end{aligned}
$$

After some simplifications

$$
\begin{aligned}
\vec{L} & =\overrightarrow{L_{1}} \times \overrightarrow{L_{2}} \\
& =\left(\begin{array}{c}
\left(y_{2}-y_{1}\right)\left(z_{4}-z_{3}\right)-\left(y_{4}-y_{3}\right)\left(z_{2}-z_{1}\right), \\
\left(z_{2}-z_{1}\right)\left(x_{4}-x_{3}\right)-\left(z_{4}-z_{3}\right)\left(x_{2}-x_{1}\right), \\
\left(x_{2}-x_{1}\right)\left(y_{4}-y_{3}\right)-\left(x_{4}-x_{3}\right)\left(y_{2}-y_{1}\right)
\end{array}\right) \\
& =(E, F, G)
\end{aligned}
$$

Taking arbitrary points ( $P_{1}$ and $P_{3}$ as examples) on $L_{1}$ and $L_{2}$, we consider the projection of line $P_{1} P_{3}$ on the common perpendicular, which in fact represents the distance between the two lines. The direction vector of line $P_{1} P_{3}$ can be described as

$$
\overrightarrow{P_{1} P_{3}}=\left(x_{3}-x_{1}, y_{3}-y_{1}, z_{3}-z_{1}\right)
$$

and the distance between the lines (axes of CNTs) is then given as

$$
\begin{aligned}
d & =\left|\operatorname{Pr} j_{\bar{L}} \overrightarrow{P_{1} P_{3}}\right| \\
& =\frac{\vec{L} \mid \overrightarrow{P_{1} P_{3}}}{|\vec{L}|}=\frac{E\left[\left(x_{3}-x_{1}\right)+F \square\left(y_{3}-y_{1}\right)+G \llbracket\left(z_{3}-z_{1}\right)\right.}{\sqrt{E^{2}+F^{2}+G^{2}}}
\end{aligned}
$$

The distance $\mathrm{d}$ between any two misaligned lines can calculated based on these equations. The distance can be 


$$
d=\sqrt{\left(x_{1}-x_{2}\right)^{2}+\left(y_{1}-y_{2}\right)^{2}}
$$

The value $d$ obtained from Eqs. (6) and (7) is introduced into Eq. (1). If at least one condition is not fulfilled, the possible new place for the CNT is generated again, and a new test is started.

\subsection{Modelling of material fatigue and moisture effect}

The 3D models were subjected to the uniaxial periodic cyclic compressive loading (displacement) $u$ along the Z-axis direction (the same values but opposite directions on both upper and lower faces of the box). All the simulations were carried out using ABAQUS/STANDARD finite element program (version 6.11). The three-dimensional 8-node linear brick finite element with reduced integration element C3D8R were used in the global scale analysis, and three-dimensional 4-node linear tetrahedron element C3D4 were used in the submodel analysis.

In order to simulate the fatigue damage evolution, two step procedure was employed [10, 29].Initial defects (with the sizes of the order of one...two finite elements) were introduced into the macroscale model by subjecting the unit cell to a quasi-static load before the cyclic loading. After the initial defects are formed, the fatigue modeling for macro-scale model is carried out. Both the crack growth onset and crack propagation are described using the Paris law: $\frac{d a}{d N}=c_{1}(\Delta G)^{c_{2}}$, where $d a / d N$ is the crack growth rate (fatigue crack length growth per loading cycle), $c_{1}$ and $c_{2}$ are material constants while $\Delta G$ represents the range of strain energy release rate, for example, the difference between the strain energy release rate at the peak and valley loading. The crack propagation analysis is carried out in the framework of the linear elastic fracture mechanics (LEFM) approach and is based on the extended-FEM method [40]. The Virtual Crack Closure Technique (VCCT) [41-43] is employed to calculate the strain energy release rate at the crack tip.

The degradation of wind turbine materials under real conditions is controlled by both mechanical and environmental loadings. The time scales of the fatigue degradation and the moisture distribution in the composite body differ drastically: while the fatigue degradation might extend over several dozens of years, the moisture is distributed over the material during minutes till hours.

That is why, as a first approximation, we neglect the time-dependency of the moisture-controlled degradation of phase properties. Instead, we assume the permanently reduced phase properties (due to the moisture effect) when simulating the material behavior of the materials under environmental loading. The degrees of reduction of the phase properties are different for fibers, interfaces, polymer, and are determined from experimental/literature data. These degrees are determined from reviewing literature data. The overview of the data on the material properties degradation is given in the section 2.5 .

\subsection{Material properties in dry state}

Below, the mechanical properties of the main phases (glass and carbon fibers, epoxy, CNT, interphases/interfaces) used in the simulations are presented. Most data are taken from literature, also from earlier works of the authors [10, 29, 34] (both because these data are relatively well justified and to ensure the comparability of results).

Polymer (epoxy) matrix: Young's modulus of $1.9 \mathrm{GPa}$, Poisson's ratio of 0.37 ; tensile strength of $68 \mathrm{MPa}$, compression strength of $88 \mathrm{MPa}$ [10].

Carbon fiber: Young's modulus $276 \mathrm{GPa}$, Poisson's ratio is 0.37 [35]; tensile and compressive strengths are $3000 \mathrm{MPa}$ and $2800 \mathrm{MPa}$, respectively [10]. Radius of carbon fiber is $4 \mu \mathrm{m}$. 
Glass fibers: radius $8 \mu \mathrm{m}$, Young's modulus is $72 \mathrm{GPa}$, Poisson's ratio is 0.26 ; tensile and compressive strengths are $2500 \mathrm{MPa}$ and $1500 \mathrm{MPa}$, respectively [29, 36].

Carbon nanotubes (CNT): The Young's modulus of SWCNT was taken $1 \mathrm{TPa}$ and the Poisson ratio is 0.2 [44]. The tensile strength is taken as $30 \mathrm{GPa}[45,46]$. The radius of carbon nanotube is $0.01 \mathrm{~nm}$ while the length of the CNT is $0.8 \mu \mathrm{m}$.

CNT/matrix interface: Young modulus of CNT-matrix interface is taken here as $3.74 \mathrm{GPa}$, following the inverse analysis of graphene-epoxy interface [34].

The interface thicknesses of both glass fiber-matrix interface and carbon fiber-matrix interface were taken as $1.0 \mu \mathrm{m}$ (slightly larger than the CNT length of $0.8 \mu \mathrm{m}$ ). According to [47, 48], the soft interface layer can be assigned the elastic modulus of $E_{\mathrm{i}}=\left(E_{\mathrm{CNT}}+E_{\mathrm{mtrix}}\right) / 20$ while the stiff interface layer can be assigned a higher Young's modulus as $E_{\mathrm{i}}=\left(E_{\mathrm{CNT}}+E_{\mathrm{mtrix}}\right) / 2$. The interface stiffness can vary therefore in the range from soft to stiff, with the ratio $E_{i} / E_{\text {matrix }}$ from 0.55 to 5.5. Thus, taking the interface layer stiffness as an average value, between "soft" and "stiff" ones, we have the elastic modulus of the fiber-matrix interface as $E_{\mathrm{i}}=\left(E_{\mathrm{fiber}}+E_{\mathrm{m} t \mathrm{ix}}\right) / 10$. Then we get: Carbon/matrix interface: the Young's modulus is $E_{\mathrm{C}-\mathrm{M}}=\left(E_{\text {Carbonfiber }}+E_{\mathrm{m} t r i x}\right) / 10=$ $27.79 \mathrm{GPa}$. Glass/matrix interface: The Young's modulus is $E_{\mathrm{G}-\mathrm{M}}=\left(E_{\mathrm{Glassfiber}}+E_{\mathrm{mtrix}}\right) / 10=7.39$ $\mathrm{GPa}$. According to [49], the interface strength between an epoxy resin and glass fiber is around 0.57 of that between carbon and epoxy.

The fatigue behavior is modelled using the Paris's law $d a / d N=c_{1}(\Delta \mathrm{G})^{c_{2}}$, where $a-$ crack length, $N$ - number of cycle. The threshold and critical strain energy release rates of different material phases and different fracture modes have been determined on the basis of literature data [50-59], inverse modelling and estimations. Using the estimation by Reeder [50] that "This is generic to any material with pure mode ratios of 3 and $6,\left(G_{\mathrm{IIc}} / G_{\mathrm{Ic}}\right.$ and $G_{\mathrm{IIIc}} / G_{\mathrm{Ic}}$, respectively) which are reasonable values..."., we could determine the $G_{\mathrm{II}}$ IIIc values from $G_{\mathrm{I}, \mathrm{c}}$.

For the strain energy release rate for fibers, we used the formulation by Pinho et. al. [53]:

$$
\left.G_{I c}\right|_{\text {fiber }}=\left.2 G_{I c}\right|_{\text {laminate }}-\left.G_{I c}\right|_{\text {matrix intra }}
$$

here, $\left.G_{\text {Ic }}\right|_{\text {fiber }},\left.G_{\text {Ic }}\right|_{\text {laminate }}$ and $\left.G_{\text {Ic }}\right|_{\text {matrix }}$ stands for the critical strain energy release rate for fiber, the fiber reinforced laminate and the matrix, respectively. Other data are listed below, with references:

- Matrix: $\mathrm{G}_{I t h}=0.06 \mathrm{~kJ} / \mathrm{m}^{2}$ [54], $\mathrm{G}_{I c}=0.17 \mathrm{~kJ} / \mathrm{m}^{2}$ [54], $\mathrm{G}_{I I t h}=0.24 \mathrm{~kJ} / \mathrm{m}^{2}, \mathrm{G}_{I I c}=0.49 \mathrm{~kJ} / \mathrm{m}^{2}[54]$, $\mathrm{G}_{\text {IIIth }}=0.306 \mathrm{~kJ} / \mathrm{m}^{2}, \mathrm{G}_{\text {IIIC }}=0.49 \mathrm{~kJ} / \mathrm{m}^{2}[54]$.

- Glass fiber: $\mathrm{G}_{I t h}=0.068 \mathrm{~kJ} / \mathrm{m}^{2}$ (Eq. (8) and [55]), $\mathrm{G}_{I c}=0.288 \mathrm{~kJ} / \mathrm{m}^{2}$ (Eq. (8) and [55]), $\mathrm{G}_{I I t h}$ $=0.59 \mathrm{~kJ} / \mathrm{m}^{2}$ (Eq. (8) and [55]), $\mathrm{G}_{I I c}=1.53 \mathrm{~kJ} / \mathrm{m}^{2}$ (Eq. (8) and [55]), $\mathrm{G}_{I I I t h}=0.994 \mathrm{~kJ} / \mathrm{m}^{2}$ (Eq. (8) and [[51]), $\mathrm{G}_{I I I c}=1.21 \mathrm{~kJ} / \mathrm{m}^{2}$ (Eq. (8) and [51]).

- Carbon fibers: $\mathrm{G}_{I t h}=0.098 \mathrm{~kJ} / \mathrm{m}^{2}$ (Eq. (8) and [57]), $\mathrm{G}_{I c}=0.636 \mathrm{~kJ} / \mathrm{m}^{2}$ (Eq. (8) and [56]), $\mathrm{G}_{\text {IIth }}=0.712 \mathrm{~kJ} / \mathrm{m}^{2}$ (Eq. (8) and [58]), $\mathrm{G}_{\text {IIc }}=3.744 \mathrm{~kJ} / \mathrm{m}^{2}$ (Eq. (8) and [58]), $\mathrm{G}_{\text {IIIth }}=1.598$ $\mathrm{kJ} / \mathrm{m}^{2}, \mathrm{G}_{\text {IIIc }}=7.978 \mathrm{~kJ} / \mathrm{m}^{2}$.

- Glass-matrix interface: $\mathrm{G}_{I t h}=0.064 \mathrm{~kJ} / \mathrm{m}^{2}$ [55], $\mathrm{G}_{I c}=0.229 \mathrm{~kJ} / \mathrm{m}^{2}$ [55], $\mathrm{G}_{I I t h}=0.415 \mathrm{~kJ} / \mathrm{m}^{2}$ [55], $\mathrm{G}_{I I c}=1.01 \mathrm{~kJ} / \mathrm{m}^{2}$ [55], $\mathrm{G}_{\text {IIIth }}=0.650 \mathrm{~kJ} / \mathrm{m}^{2}$ [51]), $\mathrm{G}_{I I I c}=0.850 \mathrm{~kJ} / \mathrm{m}^{2}$ [51]);

- Carbon-matrix interface: $\mathrm{G}_{I t h}=0.079 \mathrm{~kJ} / \mathrm{m}^{2}[57], \mathrm{G}_{I c}=0.403 \mathrm{~kJ} / \mathrm{m}^{2}[56], \mathrm{G}_{I I \mathrm{th}}=0.476 \mathrm{~kJ} / \mathrm{m}^{2}$ [58], $\mathrm{G}_{I I c}=2.117 \mathrm{~kJ} / \mathrm{m}^{2}[58], \mathrm{G}_{\text {IIth }}=0.952 \mathrm{~kJ} / \mathrm{m}^{2}, \mathrm{G}_{\text {IIIc }}=4.234 \mathrm{~kJ} / \mathrm{m}^{2}$.

Finally, two material constants $c_{1}, c_{2}$ from [40] were used: $c_{1}=2.44 \times 10^{6}$ and $c_{2}=10.61$.

\subsection{Changing material properties under environmental (moisture) loading: Overview of literature and data collection}


In order to evaluate the effect of environmental loading on the lifetime of various composites, we carried out an overview of literature data on the humidity effect on the mechanical properties and strength of the phases.

Due to the expected off-shore location of the large wind turbines, we consider the effect of seawater on the phase properties. The relative humidity in air is taken as 60\% [60].

Below, an overview of literature data and available estimations of the stiffness and strength reduction due to the humidity under given conditions are presented. These data are included in our simulations as input data.

As noted in [61, 62], moisture absorption causes plasticization and swelling of epoxy matrix, and that weakens the interfacial strength between epoxy and reinforcements, degradation of crosslinks and segments rigidity. Let us consider all the main phases in the materials and the dependences of their properties on the long term high humidity:

Polymer (epoxy) matrix: Zafar et al . [63] observed that Young modulus of epoxy is reduced by $5 \%$ and tensile strength is reduced by $15 \ldots 18 \%$ due to moisture. As observed by Mei Li [64], epoxy matrix can absorb up to $2.2 \%$ moisture. (Chawla [65] however noticed that matrices can absorb only up to $1 \%$ of weight).

Carbon fiber: According to [65], "the carbon fiber itself is unaffected by moisture", so the Young's modulus of carbon fiber under moisture condition will be the same as the dry condition. According to [63], the maximum applied stress before the fiber fracture is reduced in seawater by 1.33 times (after 60 hours)...2 times (after 230 hours). The $\mathrm{G}_{I C}$ remains almost constant as a result of moisture [49], while $\mathrm{G}_{I I C}$ is reduced drastically, 2.04 times. According to [66], carbon fiber has the $\mathrm{G}_{I c}=0.860 \mathrm{KJ} / \mathrm{m}^{2}$ and $\mathrm{G}_{I I C}=3.076 \mathrm{KJ} / \mathrm{m}^{2}$, respectively under humidity condition.

Glass fibers: As noted by Li [64], the tensile strength of glass fibers can be reduced up to $20 \%$ if the moisture content is above 1\%. In Guedes et al.'s work [67], they present that the critical strain energy release rate in model $\mathrm{I}, \mathrm{G}_{I C}$, show a decrease between $5 \%$ and $10 \%$ when conditioned in water. According to [66], glass fiber has the $\mathrm{G}_{I c}=2.152 \mathrm{KJ} / \mathrm{m}^{2}$ and $\mathrm{G}_{I I c}=4.668$ $\mathrm{KJ} / \mathrm{m}^{2}$, respectively under humidity condition.

Carbon nanotubes (CNT): CNT properties are not changed under changing humidity conditions.

Carbon/matrix interface: According to [63], the maximum applied stress before the interfacial failure is reduced by 1.9 times after 60 hours in seawater. Van der Wal [68], referring to Ray [49] noticed that epoxy carbon interface is reduced by $10 \%$ at high temperature under the humidity effect. Considering the interface as a three layer multilayer [69] (fiber/sizing interface with covalent chemical bonding; an interphase of oligomers with increasing crosslink density towards the fiber/sizing interface and the sizing/epoxy interface with covalent chemical bonding), van der Wal [68] noted that reaction with water and the formation of the microscopic solution can take place probably in oligomer phase. Grant and Bradley [70] studied the degradation of graphite/epoxy composites due to sea water immersion. Through observation by scanning electron microscopy (SEM), they found out that the measured $17 \%$ decrease in transverse tension strength was associated with the degradation of the interface.

CNT/matrix interface: According to [61], tensile strength of unmodified CNT/epoxy composite is $16 \%$ lower in seawater state than in dry state; Young modulus is $5 \%$ lower, fracture load and toughnes-66\% lower, $\mathrm{K}_{I C}-40 \%$ lower. In [61], the fracture surface (of unmodified CNT/epoxy) showed brittle fracture in dry state and "delaminated epoxy matrix due to tear down" in humid composite. Jen and Huang [71], however, studied fracture surface on 
CNT/epoxy nanocomposites, and did not observe the visible increase in the length of pulled out CNTS due to the moisture effect (but did observe it due to the combined moisture and high temperature effects).

Glass/matrix interface: According to the experiments by Ray [49], the ILSS (interlaminar shear stress) of both carbon and glass /epoxy interfaces are reduced by 1.5 times (while it is 120 for carbon and 27 for glass in dry conditions; the same numbers are mentioned in [68], around 100 and $27 \mathrm{MPa}$ ). The authors of [72] noted that the mode $I$ interlaminar fracture toughness decreases "upon water absorption for the glass fiber laminates, while the carbon fiber materials showed an increase in $\mathrm{G}_{I C}$ under the same conditions. Mode II interlaminar fracture toughness as well as flexural modulus and flexural strength were observed to decrease upon water absorption, and to recover slightly after water desorption." Also, Adams and Singh [73] observed that glass/polymer interfaces are much more severely degraded due to the moisture than the carbon/polymer interfaces.

The parameters $c_{1}$ and $c_{2}$ of Paris's law $d a / d N=c_{1}(\Delta \mathrm{G})^{c_{2}}$ have been obtained as follows:

For the polymer matrix, the experimental data of the delamination growth rate versus the strain energy release rate of fracture toughness for an epoxy material from [74] were fitted into a power law function. From the fitting curves, the parameters $c_{1}$ and $c_{2}$ were determined: $c_{1}=3.2187 \times 10^{-8}$ and $c_{2}=8.776$. The material parameters for other phases (glass and carbon fibers and interfaces) were determined using the same fitting procedures. The curves for glass fiber and glass fiber-matrix interface were fitted using the data from [75]. The resulting values are: $c_{1}=11.07 \times 10^{-2}$ and $c_{2}=22$, for glass fibers. For glass fiber/matrix interfaces, the values are $c_{1}=12.1 \times 10^{-1.1}$ and $c_{2}=16.10$, respectively. The curves for carbon fiber and carbon fiber-matrix interface were determined using the inverse method presented in work [40] and the data given in [76]. The parameter values for the carbon fibers are: $c_{1}=7.4 \times 10^{-4.3}$ and $c_{2}=29.54$, respectively. The parameters for carbon fiber-matrix interface is $c_{1}=14.1 \times 10^{-1.8}$ and $c_{2}=19.73$, respectively.

The resulting values used in the following simulations (for dry case and a case of long term $60 \%$ sea water humidity effect) are given in Table 1.

\section{Computational experiments: Effect of environmental loading on fatigue lifetime}

In this section, the effect of environmental loading, overlaying the cyclic mechanical loading, on the fatigue performances of hybrid and nanoreinforced composites is systematically studied in numerical experiments. Various microstructures of hybrid and hierarchical composites, with different fractions of carbon fibers, distribution and alignment of CNT are considered in the computational experiments. The generated unit cell models are subject to tension-compression cyclic loading with the stress ratio $R=-1$.

\subsection{Hybrid composites: Effect of carbon content on lifetime under combined environmental plus cyclic loading}

Here, we seek to investigate the effect of the hybrid structure of UD composites (with carbon and glass fibers, and varied fractions of carbon versus glass) on the fatigue performance of 
composites under combined environmental/mechanical cyclic loading. Fig. 2a shows an example of unit cell FE models with 50\% carbon fiber content.

Fig. 3a shows the calculated S-N curves for hybrid composites under pure mechanical cyclic loading (tension-compression) and under combined mechanical/environmental loading. All the data are normalized by the original maximum applied stress $(311.65 \mathrm{MPa})$ of the $50 / 50 \%$ hybrid composite without environmental loading.

One can see that the composite with pure carbon fiber reinforcement shows the highest stress and longest life under the same while the composite with glass fiber reinforcement demonstrate the lowest stress and shortest lifetime.

The stress corresponding to a given cycles number (here $1.43 \times 10^{7}$ cycles) strongly depends on the moisture effect. While the high humidity environment leads to the $14.28 \%$ reduction of the stress for the given $\mathrm{N}$ for pure carbon fiber reinforced composites, it leads to $36.53 \%$ reduction for $50 / 50 \%$ hybrid composites and even $489.24 \%$ reduction for pure glass composites. For comparison, the differences in stresses for quasi-static/low cycle case (1...2 cycles) are much lower: $7.89 \%$ (carbon), 9.91\% (50/50 hybrid) and $11.21 \%$ (pure glass).

The ratio between the stresses (corresponding to a given number of cycles) for different composites depends on the humidity as well.

For the dry cyclic (low cycle) loading, this stress for carbon composite is 1.18 times higher than that for 50/50 hybrid composite and 1.51 times higher than that for pure glass. For the case of $1.43 \times 10^{7}$ cycles (dry loading), these ratios are 1.98 and 4.12.

This corresponds also to results of Shan and Liao [77] who noticed that "because carbon fibers are resistant to water and dilute acid, glass-carbon hybrid composites as a whole are more resistant to stress corrosion than all-glass fiber composites". They demonstrated experimentally that hybrid carbon/glass composites show much higher lifetime than pure glass composites under environmental plus mechanical cyclic loading, and observed 500\% fatigue life difference for wet hybrid samples and wet pure glass samples [77, 78]. Selzer and Friedrich [79] observed 7...15\% reduction of fatigue lifetime for the carbon fiber reinforced composites under dry and high moisture conditions. These numbers correspond qualitatively to the above estimations.

\subsection{CNT reinforced composites: Effect of secondary CNT reinforcement on fatigue resistance under cyclic loading}

In this section, we investigate the effect of secondary CNT reinforcement on the fatigue performance of composites under mechanical tension-compression cyclic loading.

Fig. 2bc shows some examples of macro-micro FE unit cell models of composites with CNT reinforcements. The CNT reinforcement is localized in the fiber/matrix sizing (interface layer). The volume content is $0.05 \%$.

Fig. $3 b$ shows the calculated S-N curves for hybrid composites with/without CNT reinforcements under pure mechanical cyclic loading (tension-compression) and under combined mechanical/environmental loading. One can see that the CNT enhances the fatigue performance (maximum stress and lifetime) in all considered composites.

Again, considering the stress corresponding to a given cycles number (again, $1.72 \times 107$ cycles), we can see that the effect of CNT reinforcement strongly depends on the kind of loading. While CNT reinforcement always increases the fatigue resistance, it works differently for very low cycle loading and high cycle loading. For the very low cycle loading, the CNT reinforcement leads to $25 \% \ldots 43 \%$ increase in the stress, while for the 
millions of cycles, the CNT effect increases the stress by $64 \ldots 120 \%$. It is of interest also that while for quasi-static/low cycle loading, the strongest effect is observed for carbon composites ( $43 \%$, versus $25 \%$ for pure glass and $32 \%$ for hybrids), the strongest effect of high cycle loading is observed for glass fiber composite (120\%, versus $64 \%$ for pure carbon and $107 \%$ for hybrids).

The ratio between the stress (corresponding to a given number of cycles) for different composites slightly depend on the CNT reinforcement: this stress for carbon composites is (for high cycle fatigue) $43 \%$ (no CNT)...80\% (with CNT) higher than that for 50/50 hybrids and 3.6 (no CNT)...4.8 (CNT) times higher than for glass composites.

Fig. 4 shows the crack interaction with the CNTs in the fiber/matrix interface. The damage mechanisms such as nanotube breaking, bridging and pull-out are observed. The same damage and toughening mechanisms were observed on the fatigue crack surfaces of CNT/polymer nanocomposites analyzed by Jen and Huang [80]. Knoll et al. [81] also observed 2 to 5 fold increase in the fatigue life of carbon fiber composites due to the MWCNT secondary reinforcement.

\subsection{Environmental loading of hybrid composites with secondary CNT reinforcement}

In this section, we investigate the effect of secondary CNT reinforcement on the fatigue performance of composites under combined environmental/mechanical cyclic loading.

Fig. 3c shows the S-N curves of 50/50 glass/carbon fiber reinforced hybrid composites with secondary CNT reinforcement under cyclic fatigue with high humidity. Considering the stress corresponding to a given cycles number $\left(1.72 \times 10^{7}\right.$ cycles $)$, we can see that the effect of environmental (moisture) loading on the fatigue behavior of CNT reinforced composites in general follows the effect of moisture on the properties of hybrid composites without CNT reinforcement. One can see that the moisture effect on the CNT reinforced glass composites is weaker than on pure glass composites: the stress is only 3.5 times higher for mechanical high cycle loading and $35 \%$ higher for mechanical low cycle fatigue than for combined mechanical + environmental loading (compared with 5 times higher for non-CNT high cycle case) and $65 \%$ higher for low cycle case). For pure carbon composites, the CNT reinforcement doesn't have visible effect of the moisture resistance.

These results correspond to a number of experimental studies. So, Loos et al. [82] observed the increase of fatigue lifetime by $1550 \%$ in the high-cycle, low-stress amplitude regime due to the small additions of CNTs. The crack propagation rate in epoxy is reduced by an order of magnitude if $0.5 \mathrm{wt} \%$ CNTs is added [83]. The authors of [84] demonstrated that fatigue crack growth rates can be reduced up to 20-times by controlling CNT parameters, namely, choosing CNTs with smaller diameter, increasing the CNT length and improving its dispersion.

\subsection{Effect of the orientation of secondary CNT reinforcement on the composite performances}

In this section, the effect of the orientation of the secondary CNT reinforcements (aligned versus randomly oriented) on the fatigue behavior under high humidity conditions is considered. We consider 50/50 glass/fiber reinforced hybrid composites with various CNT secondary reinforcements (aligned along the fibers and randomly oriented).

Fig. 5 shows the results of the fatigue analysis (a) and the unit cell models of composite with CNT reinforcements (b). The stress values are normalized by the maximum applied stress of 
the aligned CNT reinforced hybrid composite without moisture effect (524.41 MPa). One can see that the composite with aligned CNTs in the sizing is much stronger than that with randomly oriented CNTs. The stress level of the composite with aligned CNTs, corresponding to low level cycle fatigue/static loading, is $17 \%$ higher than that with random CNTs (under dry conditions). The number increases to $22 \%$ under high humidity conditions.

The (mis)orientation of CNTs has a strong influence on the composite sensitivity to humidity as well: the low cycle fatigue stress is reduced by $4 \%$ as a result of high humidity if the CNTs are aligned, and by $9 \%$ if they are random oriented. The stress, corresponding to the long cycle loading (here, $1.43 \times 10^{7}$ ) stress is reduced by $26 \%$ as a result of high humidity if the CNTs are aligned, and by $31 \%$ if they are random oriented.

\subsection{Effect of CNT distribution (fiber sizing vs. matrix) on the composite performances}

In this subsection, we seek to study the effect of the CNT distribution/location on the fatigue resistance of the composites. The cases of hybrid composites with CNTs localized either in the fiber sizing or distributed in the matrix are considered. The total number of CNTs in the model $\left(9.450 * 10^{5}\right)$ is fixed and the same in both cases. Apparently, the content of CTts in the sizing is therefore much higher than in the matrix $(0.02 \%$ is the model with nanoreinforced sizing, and $0.005 \%$ in the model with CNTs in the matrix). They have been defined following the procedure described in [29]. All the CNTs are random arranged in either fiber sizing or matrix.

Fig. 6a shows S-N curves of hybrid composite with secondary CNT reinforcements in fiber sizing or in matrix, subject to the mechanical cycling loading with and without high humidity. The examples of the unit cell models are shown in Fig. 6bc. It is seen that the composite with CNT reinforcements in fiber sizing show the better fatigue performance than those with the CNT reinforcements in matrix, both in dry and high humidity conditions.

The stress level strongly depends on the location of the CNT reinforcements and the moisture effect, but these dependences are different for different composites. The high humidity leads

to the $14.3 \%$ reduction of the stress for the given amount of cycles $N=1.43 \times 10^{7}$ for hybrid composites with CNT reinforcements in fiber sizing, and to even higher $25.5 \%$ reduction for hybrid composite with CNT reinforcements in matrix. For comparison, the differences in stresses for quasi-static/low cycle case (1...2 cycles) are much lower, which are $4.2 \%$ and $8.4 \%$ for the hybrid composite with CNT reinforcements in fiber sizing and matrix, respectively.

The conclusion that the CNT reinforcement in the fiber sizing increases drastically both the fatigue lifetime and the moisture sensitivity of the composites, much more efficiently than for the CNTs distributed in the matrix, corresponds also the observations from [85] about nanostructured interfaces as a best way to enhance the materials strength.

\subsection{Effect of off-axis loading}

While most material testing procedures are based on axial tensile or compression loading, the wind blade composites are subject to off-axis, often multiaxial, compression plus shear loading [86].

In his section, we seek to investigate the effect of the CNT reinforcement on the fatigue lifetime under off-axis cyclic loading, under dry and high humidity conditions. The angle 
between fibers and loading vectors in the off-axis model was $12 \%$. The two models have the same fiber and CNTs volume fraction and loading condition.

Fig. 7 shows S-N curves of hybrid composite with and without secondary CNT reinforcements, subject to the axial and off-axis mechanical cycling loading with and without high humidity. As expected, the fatigue life is much lower under off-axis loading than under axial loading.

The stresses corresponding to low cycle loading and to the given cycle number, $1.43 \times 10^{7}$, are $12.2 \%$ and $14.1 \%$ lower for the off-axis loading, respectively. For the case under high humidity conditions, these values are lower for the off-axis loading by 7.6 and $9.7 \%$ respectively.

Comparing the stresses corresponding to the low and high cycle numbers for non-CNTreinforced and CNT reinforced hybrid composites and dry/humid cases, one can see that the stress is reduced by $30 \%$ in dry case (without CNT) due to the off-axis loading. In humid conditions, the stress is reduced much stronger: $45 \%$ for low cycle/static and 6 times for high cycle loading. In the case with CNT, the stress is reduced by $13 . .23 \%$ in dry conditions, and by only $19 . .30 \%$ in humid conditions. This is an important conclusion: the CNT reinforcement allows to drastically reduce the fatigue life sensitivity to off-axis loading, also under high humidity conditions.

\section{Applicability to wind turbine blade materials}

In this section, we seek to evaluate the feasibility of using hybrid and nanoreinforced composites in wind blades, as a replacement for the currently used glass fiber/epoxy composites. As noted above, the reliability of wind turbine blades is determined in many cases by the matrix and sizing controlled properties, i.e. those which are controlled and influenced by the secondary nanoreinforcement. Thus, the nanoreinforced and hybrid composites have a great potential to be used in order to improve the wind blade materials performances.

The important requirement toward wind blade materials is their economic efficiency, i.e. the gains in strength and lifetime should overweight the additional costs. Let us make a rough estimation of the economic feasibility of new materials for wind energy applications.

The cost of energy over whole lifetime of the wind turbine can be estimated using the following formula [87]:

$C o E_{\text {total }}=\frac{C^{*} F C R+M}{P_{\text {Avg }} T}$

where $P_{A v g}$ - average power generation per hour, T - lifetime in hours, FCR - fixed charge rate (taken in [87] as 10\%), $\mathrm{M}$ - maintenance costs (taken as $2 \%$ installed capital costs in [87]), $\mathrm{C}-$ capital investment for a turbine, which is calculated as [88]: $C=c P_{r a t}, P_{r a t}$-rated (maximum) turbine power, $c$ - coefficient, $c=1100 € / \mathrm{kW}$ (land based) or $1500 \ldots 2000 € / \mathrm{kW}$ (off-shore turbine). The average power generation $P_{A v g}$ is calculated as [88]: $P_{A v g}=\int_{U_{\text {in }}}^{U_{\text {out }}} P(U) f(U) d U$, where $\mathrm{U}$ - undisturbed wind speed, $\mathrm{f}(\mathrm{U})$ - wind speed probability density given by Weilbul distribution with shape factor $2, U_{\text {in }}$ and $U_{\text {out }}$ - start and stop wind speeds of the wind turbine, $P(U)$ - power at the wind speed $U, P(U)$ can be calculated as $C_{p} \rho A U^{3} / 2, C_{p}$ - power 
coefficient $(\leq 0.59)$, $\rho$ - air density, A -rotor swept area, $A=\pi R^{2}$, R- turbine radius. $C_{p}$ can be taken 0.45[88]. Simplifying, we have: $P_{A v g}=0.23 \pi R^{2} C_{U}$, where $C_{U}=\int_{U_{\text {in }}}^{U_{\text {out }}} \rho U^{3} f(U) d U$.

Let's assume that the cost of a wind turbine is increased by $\mathrm{C}_{\text {nano }}$ times, as a result of using nanoengineered materials. From the formula (9), one can see that if additional costs for the fabrication of a blade from nanoengineered material lead to the increase of capital investments per turbine for instance by $20 \%$, the expected increase of the lifetime of the turbine should be at least higher than that, to keep the costs of energy at the same level.

Veers and colleagues [89] derived a very simplified analytical equation linking the lifetime of a turbine component to the wind speed and materials fatigue properties:

$T=\left[C f_{0}\left(\frac{\sqrt{2} M K V_{m}}{\left(1-S_{m} / S_{u}\right)(1 / \alpha) !}\right)^{b}\left(\frac{b}{2}\right) !\left(\frac{b}{\alpha}\right) !\right]^{-1}$

where $\mathrm{C}$ and $\mathrm{b}$ - coefficient and power coefficient of S-N curve of the material, $N=C \sigma^{-b}$, f0average frequency, $S_{m}, S_{u}$ are mean stress and ultimate strength of WT material, $V_{m}-$ mean wind speed, $\alpha$ - parameter of Rayleigh law distribution for wind speed variation, $\mathrm{K}-$ stress concentration factor [90]. Collecting all the material-independent terns in a coefficient, we can rewrite equation (10) as: $T=C_{m i} \frac{\left(1-S_{m} / S_{u}\right)^{-b}}{C(M K)^{b}}\left[\left(\frac{b}{2}\right) !\left(\frac{b}{\alpha}\right) !\right]^{-1}$. Designating the cost of energy for a basic case (glass fiber epoxy composites) as $\mathrm{CoE}_{1}$, and using equation (9), we can define the allowable upper limit for $\mathrm{C}_{\text {nano }}$ as a relative increase of the lifetime of blade from each material as compared with basic cases (here, glass fiber epoxy composite):

$C_{\text {nano }}^{\max }<\frac{C o E_{2}}{C o E_{1}}=\frac{C_{2}\left(K_{2}\right)^{b_{2}}\left(1-S_{m} / S_{u 1}\right)^{-b 1}}{C_{1}\left(K_{1}\right)^{b 1}\left(1-S_{m} / S_{u 2}\right)^{-b_{2}}} \frac{\left(\frac{b_{2}}{2}\right) !\left(\frac{b_{2}}{\alpha}\right) !}{\left(\frac{b_{1}}{2}\right) !\left(\frac{b_{1}}{\alpha}\right) !}$

Where indices 1 and 2 refer to the basic case (here, glass fibers) and considered case of a composite with modified structure, respectively. These formulas are very approximate, but can give some qualitative estimations under which conditions the replacement of the traditional

Let us estimate how the materials modifications considered above influence the turbine lifetime. Table 2 shows the coefficients $\mathrm{b}$ and $\mathrm{C}$ determined in our simulations above.

Substituting these values into the formula (11), we can calculate that the replacement of the glass fibers by carbon leads to the $33.2 \%$ more lifetime. $50 \%$ replacement leads to the $12.6 \%$ increased lifetime. $0.5 \% \mathrm{CNT}$ nanoreinforcements (in fiber sizing) increase the lifetime by $16 \%$ (if the fibers are still from glass) or even $86 \%$ (if the fibers are replaced by carbon fibers). (All this for the dry conditions). For the high humidity conditions, positive effects of the structural modifications are much stronger: $43 \%$ increased lifetime of the glass fibers are replaced by carbon (10\%, if only $50 \%$ replaced), $24 \%$ increase if the glass composite is CNT nanoreinforced and $110 \%$ if both. If the carbon nanotubes in the fiber sizing are not randomly oriented but aligned, their positive effect increases by $16 \%$ additionally. Thus, one can state that the gains in the lifetime of the composites do justify some additional investments to produce the wind turbine blades from hybrid and nanoreinforced composites, with the investments in the range between 12 and $86 \%$ of the current costs. The justifiability of these 
investments becomes even more apparent when considering the blades which should work in off-shore conditions.

For comparison, Merugula and colleagues $[24,25]$ demonstrated that the addition of $1 \ldots 5 \mathrm{wt} \%$ of carbon nanofibers (CNF) to the interfaces of glass fiber reinforced epoxy composites for blades in $2 \mathrm{MW}$ and $5 \mathrm{MW}$ turbines leads to improved tensile stress and modulus, and allows $20 \%$ weight reduction of the blades, leading to the increased lifetime.

\section{Conclusions}

In this work, the potential of using hybrid and nanoreinforced composites for wind turbine and other long term cyclic, high humidity service conditions is analyzed, using computational experiments. Using 3D multiscale computational models of hybrid and nanoreinforced composites, we carry out systematic numerical experiments and determine the fatigue lifetime of composites with various structures under ideal dry conditions and expected off-shore service conditions (seawater humidity 65\%). Having determined the local properties of the phases (carbon and glass fibers, CNT, epoxy, interface layers) under both dry and high humidity conditions from literature review, we introduced these data in our computational models and compared the fatigue performances of different composite structures.

The computational studies allowed to draw the following conclusions. Carbon reinforced composites have much better fatigue lifetime than glass reinforced composites (the 50/50 hybrids lie in between). The lifetime of composites depends strongly on the humidity conditions, and the glass fiber composites are most sensitive to humidity, while the carbon composites are least sensitive to it. The secondary CNT reinforcement ensures a much higher lifetime of composites, especially, when it is localized in the fiber sizing. The CNT reinforced glass fiber composites show lower humidity sensitivity than pure glass reinforced composites; yet, this effect is much weaker for carbon fiber composites. The CNT reinforcement in composites allows to reduce the sensitivity of the composite fatigue lifetime to the off-axis loading, also under high humidity conditions. The carbon fiber reinforced composites with CNT reinforcement is the fiber sizing have the best potential for use in the large wind turbine blades, especially, off shore turbines. Also, hybrid carbon/glass composites with the secondary CNT reinforcement have a high potential to replace the common composites, with sufficient improvement of the materials performances.

Acknowledgement: The author gratefully acknowledges the financial support of the Danish Council for Strategic Research (DSF) via the Sino-Danish collaborative project "High reliability of large wind turbines via computational micromechanics based enhancement of materials performances" (Ref. no. 10-094539). Furthermore, the author is grateful to the DSF for its support via the Danish Centre for Composite Structures and Materials for Wind Turbines (DCCSM) (Contract no. 09-067212).

\section{References:}

1. L. Mishnaevsky Jr., et al, Wind Energy, Vol. 15, No.1, pp, 83-97, 2012

2. P.C. Ma, Y. Zhang. Renewable and Sustainable Energy Reviews, 2014, 30, 651-660

3. L. Mishnaevsky Jr..; H.W. Zhou, R. Peng, G. Dai, H.W. Wang, Polymer nanocomposites for wind energy applications: Perspectives and computational modeling. Proc. Int. Conf. Nanomaterials: Application \& Properties, Vol. 2, No 4, 04NEA07 (4 pp)(2013)

4. Ong C.-H. and Tsai S. W. (2000) The use of carbon fibers in wind turbine blade design: A SERI-8 Blade Example SAND2000-0478, Sandia National Laboratories Contractor Report 
5. Ashwill, T.D. (2009) Materials and Innovations for Large Blade Structures: Research Opportunities in Wind Energy Technology, 50th AIAA Structures, Structural Dynamics, \& Materials Conference Palm Springs, May, 2009

6. Grande, J. A. (2008), Plastics Technology, 54 (10) 68-75

7. Haberkern H. (2006), Reinforced Plastics, 50,(4) 28-33

8. L. Mishnaevsky Jr., G.Dai, , Composite Structures, 117 (2014) 156-168

9. L. Mishnaevsky Jr., G.M. Dai, Computational Materials Science, Vol. 81, 2014, pp. 630-640

10. G.M. Dai, L. Mishnaevsky Jr., Composites Science \& Technology, Vol. 94, 2014, pp. 71-79

11. P. W. Manders, M. G. Bader, J Materials Science August 1981, Volume 16, Issue 8, pp 2246-2256

12. M. Y.M. Chiang et al. Composites Science and Technology, Vol. 65, No. 11-12, 2005, Pp. 1719-1727

13. J. Gutans, V. Tamuzs, Theoretical and Applied Fracture Mechanics, Vol. 7, No. 3, 1987, Pp. $193-200$

14. P. Bortolotti. Carbon glass hybrid materials for wind turbine rotor blades, Master Thesis Delft University of Technology, April 23, 2012

15. L.N. Yao, T.W. Chou, , Composite Structures, Vol. 12, No. 1, 1989, Pp. 27-37

16. J. Summerscales, D. Short, Composites, Vol. 9, No. 3, July 1978, Pp. 157-166

17. P.W. Sonparote, S.C. Lakkad, Fibre Science and Technology, Vol. 16, No. 4, June 1982, Pp. $309-312$

18. A. M. Díez-Pascual et al, Current Opinion in Solid State and Materials Science, In Press, 2013

19. N. De Greef et al, ,Carbon Vol.49, Issue 14, 2011, Pages 4650-4664

20. A. Godara, et al, , Composites Science and Technology, Volume 70, Issue 9, 2010, Pages 1346-1352

21. A. Godara et al., , Carbon, Vol.47, 12, 2009, pp. 2914-2923

22. N. Siddiqui, M. Sham, B. Tang, A. Munir, J. Kim, Compos A (2009), pp. 1606-1614

23. J. Zhu et al., Compos Sci Technol 67 (7-8) (2007), pp. 1509-1517

24. L. Merugula, V. Khanna, B.R. Bakshi,.Environ Sci Technol. 2012 Sep 4;46(17):9785-92..

25. L. Merugula, V. Khanna, B.R. Bakshi Comparative life cycle assessment:reinforcing wind turbine blades with carbon nanofibres. In: Sustainable Systems and Technology (ISSST), 2010 IEEE Symposium on Sustainable Systems and Technology, Washington, D.C., May 17-19, 2010, pp. 1-6.

26.

E. Bekyarova et al., , J Phys Chem C 111 (2007), pp. 17865-17871

27.

E. Bekyarova, et al, Langmuir 23 (7) (2007), pp. 3970-3974. E.

28.

S.S. Wicks, et al, , Composites Science and Technology, Vol 70, No 1, 2010, pp 20-28

29.

G.M. Dai, L. Mishnaevsky Jr., Composites Science \& Technology, Vol. 91, 2014, pp. 71-81.

30.

G.M. Dai, L. Mishnaevsky Jr., , Composites Science \& Technology, 74 (2013) 67-77

31.

L. Mishnaevsky Jr and P. Brøndsted, Materials Science \&Engg: A, Vol.498, No. 1-2, 2008, pp. 81-86

32.

C.Y. Li, Tsu-Wei Chou.. Composites: Part A 2009; 40: 1580-6.

33.

C.Y. Li, Tsu-Wei Chou.. Composites Science and Technology 2008; 68: 3373-9.

34.

G.M. Dai, L. Mishnaevsky Jr., , Computational Materials Science, doi: 10.1016/j.commatsci.2014.08.011

35.

L. Mishnaevsky Jr and P. Brøndsted, Composites Sci \& Technol, Vol. 69, 3-4, 2009, pp. 477-484

36.

V.I. Kushch, et al, Int. J. Eng. Sci., Vol. 49, No.1, 2011, pp. 17-29

37.

R.D. Peng et al Computational Materials Science, 60 (2012) 19-31

38. H.W. Wang et al Composites Scie \& Technol, Vol. 71, No. 7, 2011, pp- 980-988

39. E.T. Thostenson et al, J Applied Physics 2002; 91: 6034-7.

40. R. Krueger. Development of a benchmark example for delamination fatigue growth prediction. NASA/CR-2010-216723, NIA report No. 2010-04.

41. Rybicki EF, Kanninen MF. A finite element calculation of stress intensity factors by a modified crack closure integral. Eng Fract Mech 1977;9:931-8.

42. Mishnaevsky Jr L, Lippmann N, Schmauder S. Int J Fracture 2003;120:581-600.

43. Krueger R. Appl Mech Rev 2004;57:109-43.

44. Sanche-Portal D., et al, . Phys Rev B 1999; 59: 12678-88.

45. Yu MF, et al. Phys Rev Lett 2000; 84: 5552-5.

46. Yu MF, et al, Science 2000; 287: 637-40.

47. P. Joshi, S.H. Upadhyay. Computational Materials Science 2014; 87: 267-273.

48. P.P. Gohil. J Reinofrced Plastics and Composites 2010; 29: 685-699.

49. B.C. Ray. J Colloid and Interface Science 2006; 298: 111-117. 
50. JR Reeder. 3D Mixed-mode delamination fracture criteria-an experimentalist's perspective. NASA Langley Research Center, M/S 188E, Hampton VA 23681-2199, USA.

51. WC Liao, CT Sun.. Comp Sci \& Tech, 56(4): 489-499.

52. JR Reeder. A bilinear failure criterion for mixed-mode delamination. Composite Materials: Testing and design, ASTM STP 1206, Camponeschi, Jr., Ed. ASTM Int., W. Conshohochen, PA, PP. 303-322.

53. ST Pinho, P Robinson, L Iannucci. Composites Sci. Technol. 2006; 66: 2069-2079.

54. M. König, R. Krüger, K. Kussmaul, M. v. Alberti, and M. Gädke, "Characterizing Static and Fatigue Interlaminar Fracture Behaviour of a First Generation Graphite/Epoxy Composite," in Composite Materials: Testing and Design - (13th Vol.), ASTM STP 1242, S. J. Hooper, Ed.: American Society for Testing and Materials, pp. 60-81, 1997.

55. G. B. Murri, R.H. Martin. Effect of initial delamination on mode I and mode II interlaminar fracture toughness and fatigue fracture threshold. NASA Langley Research Center, NASA-TM-104079, Hampton, Virginia 23665, USA.

56. H.S. Schwartz, J.T. Hartness. Effect of fiber coatings on interlaminar fracture toughness of composites. Toughened Composites: Symposium on Toughened Composites, Issue 937. Baltimore, MD, 1987.

57. S. Singh, E. Greenhalgh. Delamination growth in epoxy-matrix composites under cyclic loading: implications for design and certification. $8^{\text {th }}$ Europ Conf Composite Materials (ECCM-8), Naples, Italy, June, 1998.

58. T. K. O'Brien, W.M. Johnston, G.J. Toland. Mode II interfalaminar fracture toughness and fatigue characterization of a graphite epoxy composite material. NASA Langley Research Center, NASA/TM2010-216838, Hampton, Virginia 23681-2199, USA.

59. S Jose, RK Kuma, MK Jana, GV Rao. Composites Sci. Technol.2001; 61: 1115-1122.

60. S. Valsson, A. Bharat. Impact of air temperature on relative humidity-a study. Architecture-Time Space \& People, 2011; 38-41.

61. Ji Hoon Lee, Kyong Yop Rhee, Joong Hee Lee. Applied Surface Science, Volume 256, Issue 24, 1 October 2010, Pages 7658-7667

62. K.Y. Rhee, S.R. Ha, S.J. Park, H.J. Kim, D.H. Jung. Mater. Sci. Eng. A, 419 (2006), pp. 209-213

63. A. Zafar et al, Composites Science and Technology 2012; 72: 656-666.

64. Mei Li, Temperature and moisture effects on composite materials for wind turbine blades. PhD thesis, Montana state university, Bozeman, Montana, 2000.

65. K. Chawla. Composite Materials: Science and Engineering, 3rd edition. Springer; 2012.

66. F.U. Buehler, J.C. Seferis. Composites: Part A 2000; 31: 741-748.

67. R.M. Guedes, A. Sa. Journal of reinforced plastics and composites 2010.

68. J.S. van der Wal. Water Resistance of Glass Fibre Reinforced Epoxy (GFRP) and Carbon Fibre Reinforced Epoxy (CFRP) Composite. Diffusion-polumers.com, Netherlands, 2006.

69. Kinloch, A.J.. Structural Adhesives: Developments in resins and primers. Elsevier Applied Science Publishers, 1986.

70. Grant S.T., Bradley L.W.. J Composite Materials 1995; 29: 853-867.

71. Yi-Ming Jen and Chien-Yang Huang., Transactions of the Canadian Society for Mechanical Engineering, Vol. 37, No. 3, 2013.

72. F.U Buehler, J.C Seferis. Composites Part A:, Volume 31, Issue 7, July 2000, Pages 741-748

73. R.D. Adams, M.M. Singh. Composites Science and Technology, Volu56, Issue 8, 1996, Pages 977-997

74. P.E. Bretz, R.W. Hertzberg, J.A. Manson. J Materials Science 1979; 14: 2482-2492.

75. J.L. Armstrong, M.J. Matthewson.. J. Am. Ceram. Soc. 83; 2000: 3100-108.

76. Y. Nishikawa, K. Okubo, T. Fujii.. JSME International Journal 2005; 48: 73-78.

77. Y. Shan, K. Liao, , Composites Part B: Engineering, Volume 32, Issue 4, 2001, Pages 355-363

78. Y Shan, K.L. Lai, K.T. Wan, K.Liao, J Composite Materials, 200236 no. 2 159-172

79. R. Selzer, K. Friedrich. Composites Part A 1997; 28A: 595-604.

80. Y.M.Jen, Ch. Huang, Combined temperature and moisture effect on the strength of carbon nanotube reinforced epoxy materials, Trans. Can. Soc. Mech. Eng., ICETI 2012-J1082_SCI, No. 13-CSME-61, E.I.C. Accession 3519, http://www.tcsme.org/Papers/Vol37/Vol37No3Paper47.pdf

81. J.B. Knoll et al, Composites Part A, DOI: 10.1016/j.compositesa.2014.08.022 
82. M.R. Loos, J. Yang, D.L. Feke, I. Manas-Zloczower, Polym Eng Sci, 52 (2012), pp. 1882-1887

83. W. Zhang, R.C. Picu, N. Koratkar, Appl Phys Lett, 91 (2007), p. 193109

84. W. Zhang, R.C. Picu, N. Koratkar, Nanotechnology, 19 (2008), p. 285709

85. L. Mishnaevsky Jr., Composites Part B, Vol. 68, 2015, pp. 75-84

86. Thomsen, O.T. (2009) J Sandwich Structures \& Materials, Vol. 11, No. 1, p. 7-26

87. J.F. Manwell, J G. McGowan, A. L. Rogers, Wind energy explained: Theory, design and application

88. D. Veldkamp, Chances in Wind Energy. A Probabilistic Approach to Wind Turbine Fatigue Design, PhD thesis, 2006, DUWIND Delft University Wind Energy Research Institute, 290 pp.

89. P. S. Veers H. J. Sutherland T. D. Ashwill, Fatigue life variability and reliability analysis of a wind turbine blade., 1991, 5p, Sandia National Labs., Albuquerque, NM.

90. C. Lange, Probabilistic fatigue methodology and wind turbine reliability, 1996, UMI

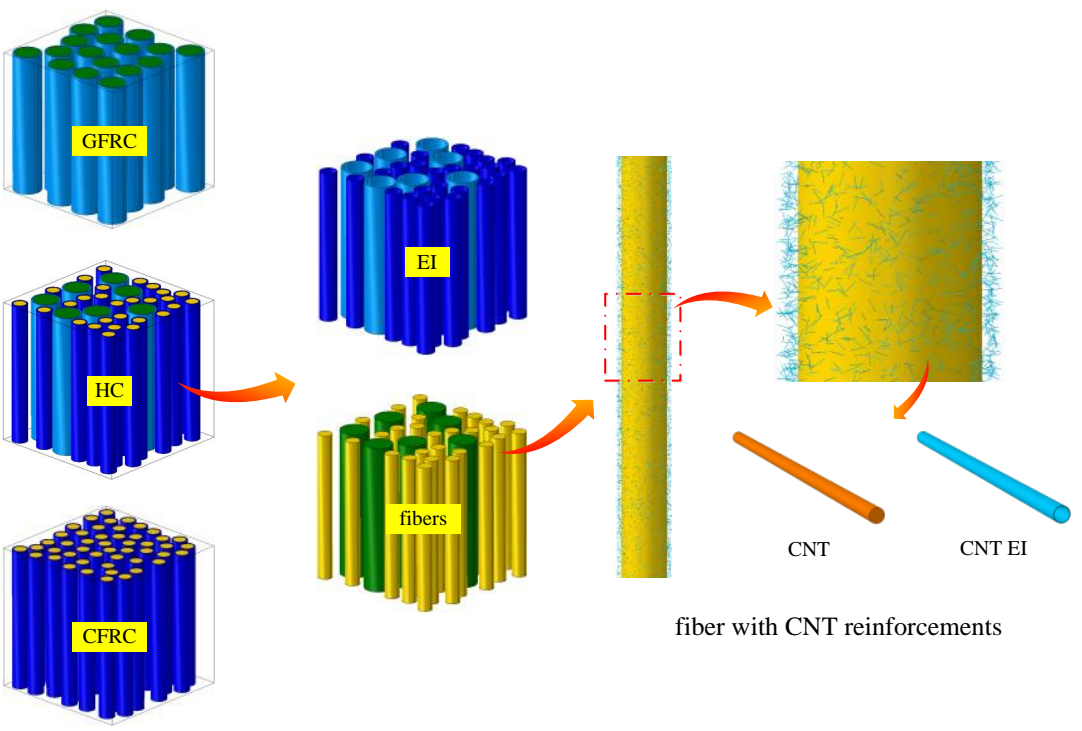

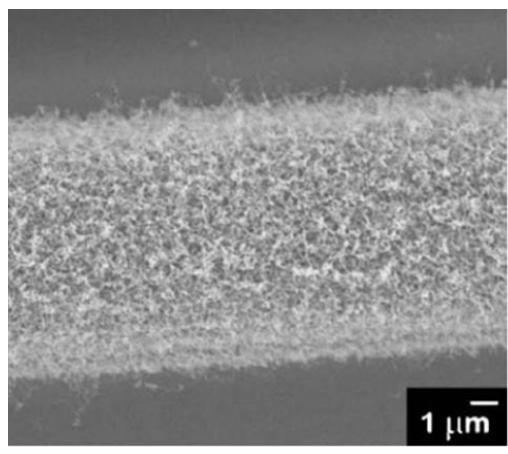

b

GFRC: glass fiber reinforced composite HC: hybrid composite CFRC: carbon fiber reinforced composite EI: effective interface

a

Fig. 1. Schema of the multiscale model, (a) and a micrograph of a carbon fiber with CNT reinforcements in fibermatrix interface (Reprinted from [39] with kind permission from Elsevier).

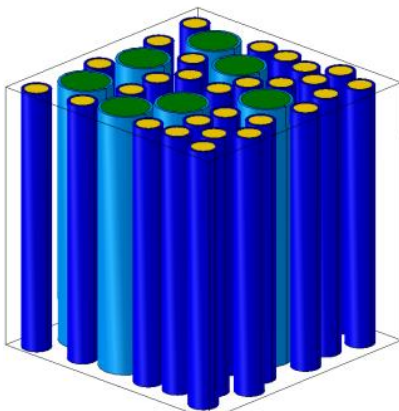

a.

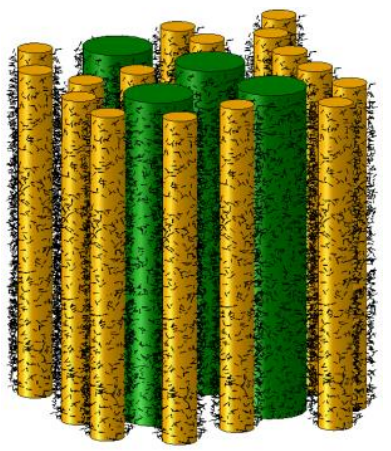

b.

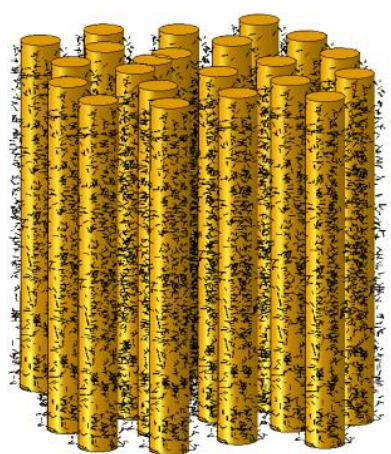

c.

Fig. 2 Examples of multielement unit cells (a) 50/50 glass/carbon hybrid composite without CNT (b) with CNT reinforcement, (c ) carbon reinforced composite with CNTs 


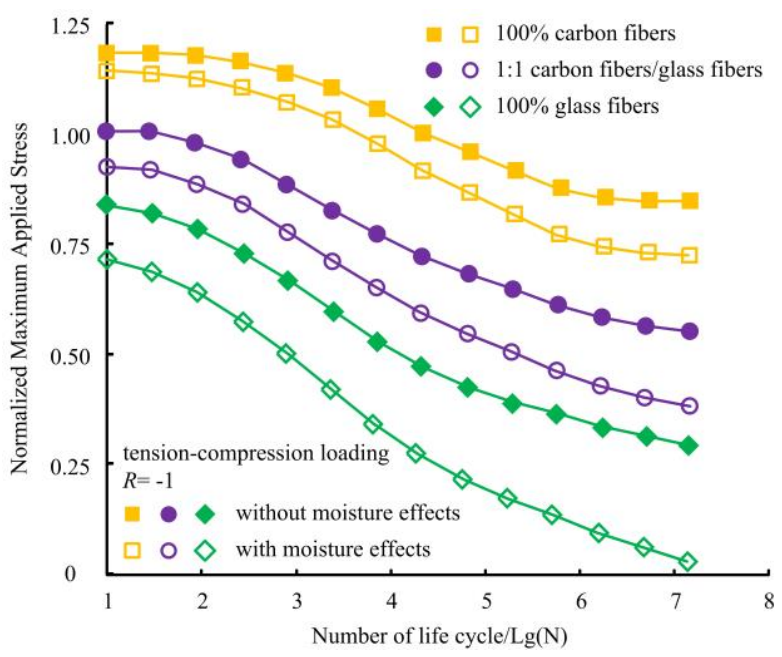

a

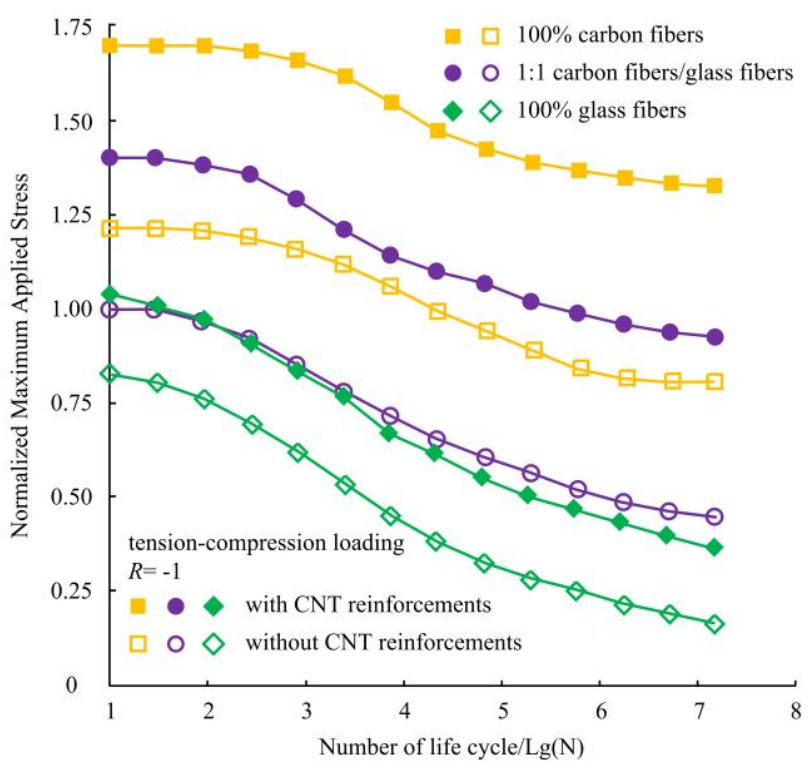

b

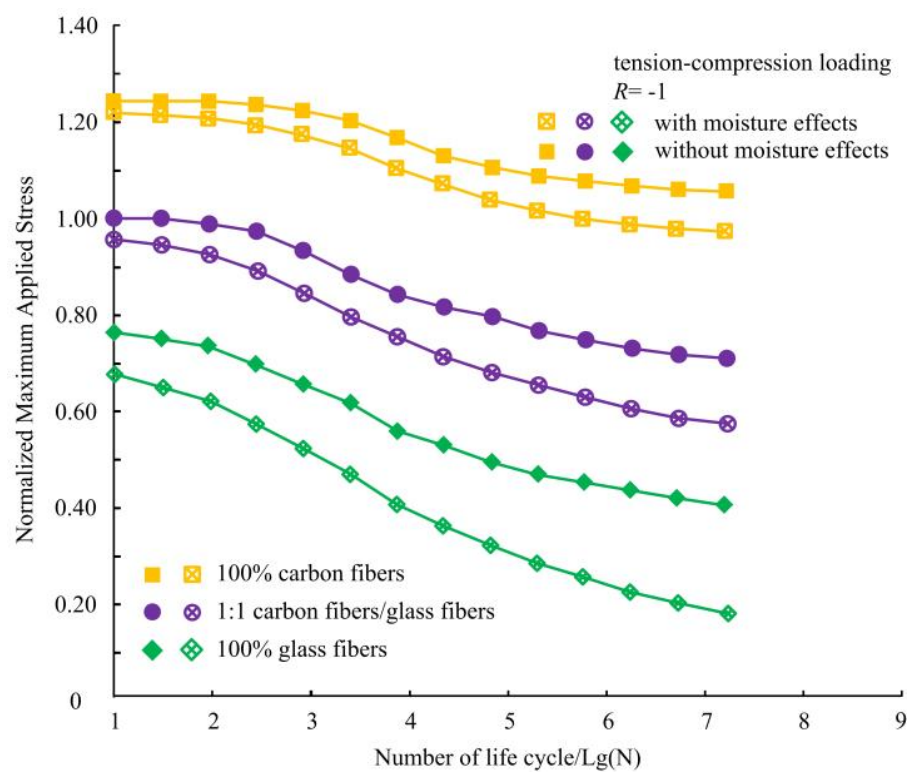

C

Fig. 3 S-N curves for hybrid composites under pure mechanical cyclic loading (tension-compression) under dry and long term high humidity conditions (a) without CNT reinforcement, and (b) with CNT reinforcement under dry and (c) with CNTs under humid conditions

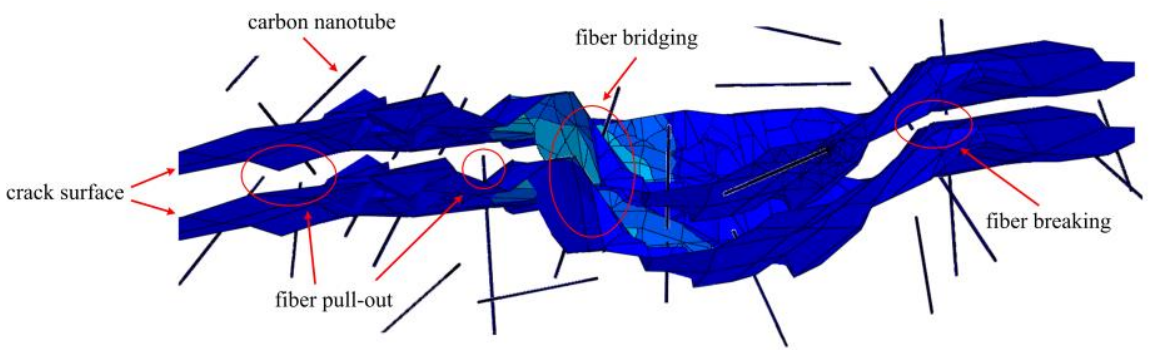

Fig. 4 Crack interaction with CNTs 


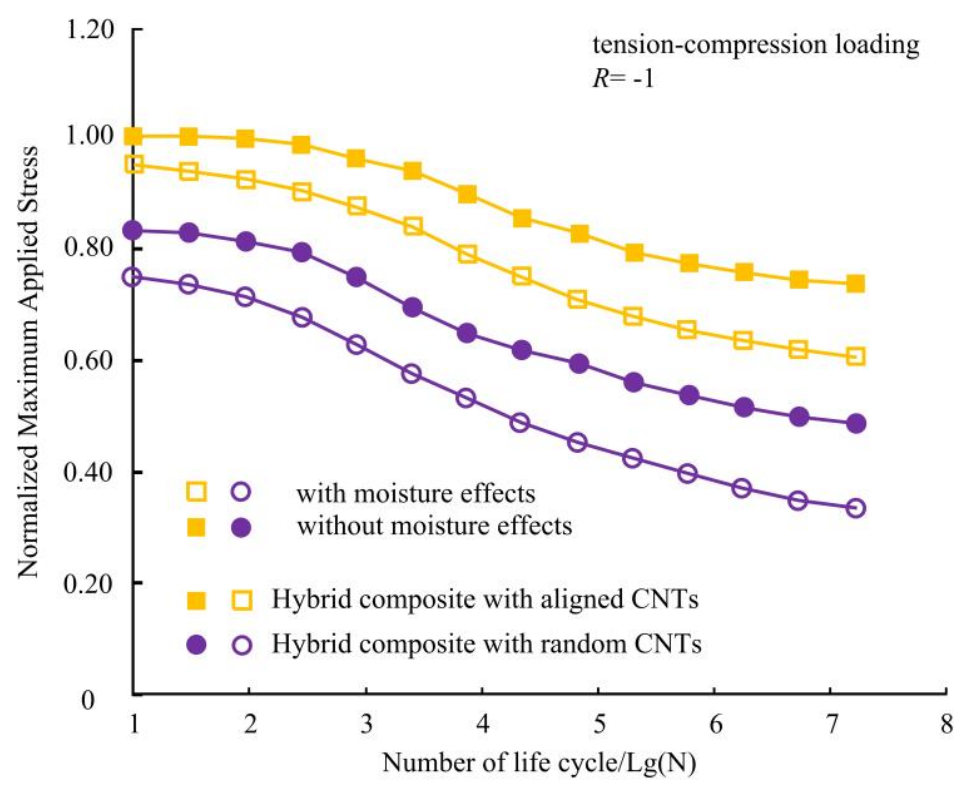

a



b

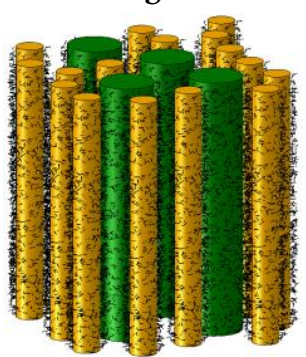

c

Fig. 5 S-N curves of the composites with different alignment of CNTs (a) and unit cell models with varied CNT alignment: b) aligned c) random
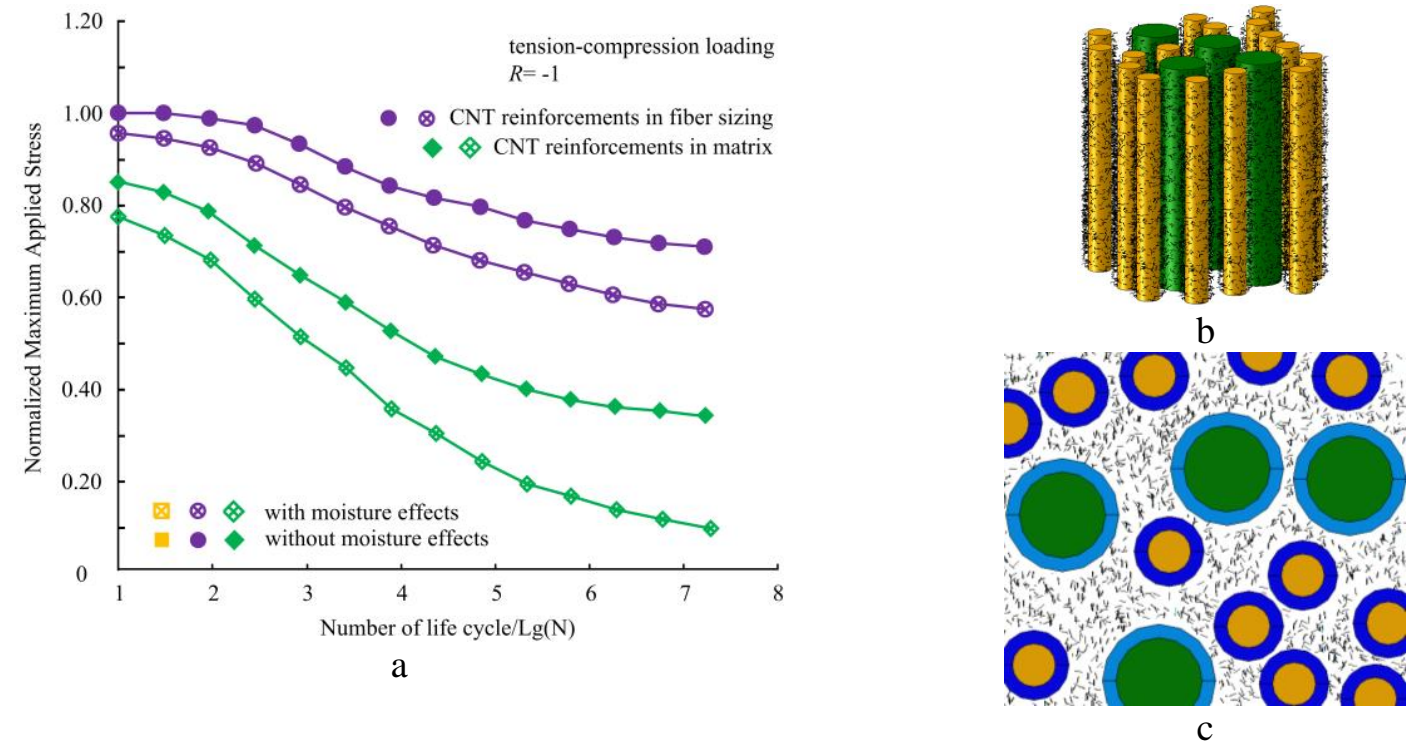

Fig. 6 S-N curves of hybrid composite with secondary CNT reinforcements in fiber sizing or in matrix (a) and examples of the models (b)
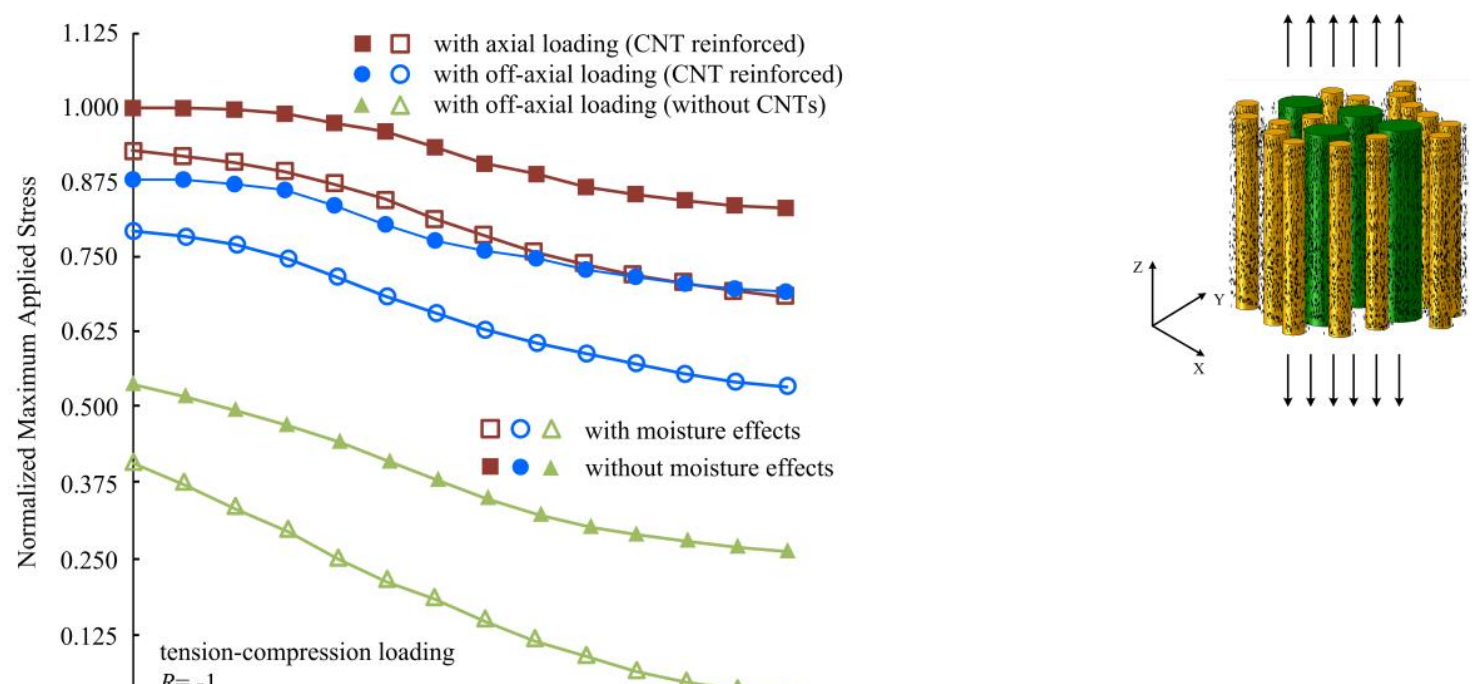


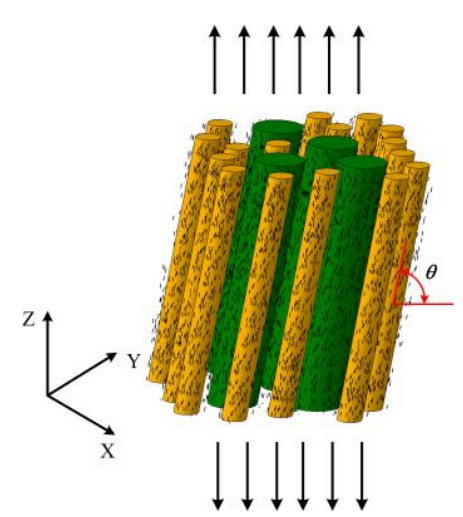

Fig. 7 S-N curves of the composites with CNT reinforcement axial loading and off-axial loading (a) and schemas of unit cell models and loading (b)

Table 1. Effect of moisture on the local phase properties

\begin{tabular}{|c|c|c|c|c|c|c|}
\hline & & Young, GPa & $G_{\mathrm{I}}, \mathrm{KJ} / \mathrm{m}^{2}$ & $G_{\mathrm{II}}, \mathrm{KJ} / \mathrm{m}^{2}$ & $c_{1}$ & $c_{2}$ \\
\hline CNT & & 2550 & - & - & - & - \\
\hline \multirow{2}{*}{$\begin{array}{l}\text { Carbon } \\
\text { fiber }\end{array}$} & Dry & 276 & 0.919 & 4.995 & $2.76 \times 10^{-8}$ & 6.4 \\
\hline & Humid & 276 & 0.860 & 3.076 & $7.4 \times 10^{-4.3}$ & 29.54 \\
\hline \multirow{2}{*}{$\begin{array}{l}\text { Glass } \\
\text { fiber }\end{array}$} & Dry & 72 & 2.302 & 5.768 & $1.26 \times 10^{-5}$ & 4.53 \\
\hline & Humid & 57.6 & 2.152 & 4.668 & $11.07 \times 10^{-2}$ & 22 \\
\hline \multirow{2}{*}{ Epoxy } & Dry & 1.9 & 0.173 & 0.648 & $2.8461 \times 10^{-9}$ & -12.415 \\
\hline & Humid & 1.805 & 0.173 & 0.324 & $3.2187 \times 10^{-8}$ & 8.776 \\
\hline \multirow{2}{*}{$\begin{array}{l}\text { IF } \\
\text { CNT/E }\end{array}$} & Dry & 3.74 & 0.447 & 1.93 & $4.253 \times 10^{-6}$ & -8.121 \\
\hline & Humid & 3.553 & 0.2682 & 1.1966 & $1.354 \times 10^{-4}$ & 14.21 \\
\hline \multirow{2}{*}{ IF C/E } & Dry & 27.79 & 0.379 & 1.70 & $2.125 \times 10^{-7}$ & 5.26 \\
\hline & Humid & 19.125 & 0.252 & 1.13 & $6.148 \times 10^{-3}$ & 22.65 \\
\hline \multirow{2}{*}{ IF G/E } & Dry & 7.39 & 0.682 & 2.245 & $5.7623 \times 10^{-7}$ & -9.542 \\
\hline & Humid & 6.72 & 0.455 & 1.497 & $3.678 \times 10^{-2}$ & 14.321 \\
\hline
\end{tabular}

(IF: interface; C/E: carbon fiber and epoxy; G/E: glass fiber and epoxy)

Table 2. Proportionality and power coefficient of S-N curve of the considered model materials

\begin{tabular}{|c|c|c|c|c|c|c|c|c|}
\hline & \multicolumn{4}{|l|}{ Dry conditions } & \multicolumn{4}{|c|}{ Humidity conditions } \\
\hline Case & $\begin{array}{l}\text { Pure glass } \\
\text { reinforced } \\
\text { composite (GRC) }\end{array}$ & \multicolumn{2}{|c|}{ Carbon RC } & $\begin{array}{l}50 / 50 \\
\text { glass/carbon } \\
\text { hybrid }\end{array}$ & Glass RC & \multicolumn{2}{|c|}{ Carbon RC } & $\begin{array}{l}50 / 50 \\
\text { glass/carbon } \\
\text { hybrid }\end{array}$ \\
\hline $\mathrm{C}, * 10^{10}$ & 2.405 & \multicolumn{2}{|c|}{3.188} & 2.703 & 2.104 & \multicolumn{2}{|l|}{3.078} & 2.486 \\
\hline $\mathrm{b}$ & 0.542 & \multicolumn{2}{|c|}{0.333} & 0.463 & 0.687 & \multicolumn{2}{|l|}{0.375} & 0.514 \\
\hline & \multicolumn{4}{|c|}{ Dry conditions, + CNT reinforcement } & \multicolumn{4}{|c|}{ Humidity conditions, + CNT reinforcement } \\
\hline Case & Glass RC & \multicolumn{2}{|c|}{ Carbon RC } & $\begin{array}{l}50 / 50 \\
\text { glass/carbon } \\
\text { hybrid }\end{array}$ & Glass RC & \multicolumn{2}{|c|}{ Carbon RC } & $\begin{array}{l}50 / 50 \\
\text { glass/carbon } \\
\text { hybrid }\end{array}$ \\
\hline $\mathrm{C}, * 10^{10}$ & 2.804 & \multicolumn{2}{|c|}{4.455} & 3.704 & 2.588 & \multicolumn{2}{|c|}{4.386} & 3.533 \\
\hline $\mathrm{b}$ & 0.486 & \multicolumn{2}{|c|}{0.318} & 0.408 & 0.557 & \multicolumn{2}{|l|}{0.338} & 0.446 \\
\hline & \multicolumn{4}{|c|}{ Dry conditions, 50/50 hybrid with CNT } & \multicolumn{4}{|c|}{ Humidity conditions, , 50/50 hybrid with CNT } \\
\hline Case & \multicolumn{2}{|c|}{$\begin{array}{c}\text { Aligned CNTs in fiber } \\
\text { sizing }\end{array}$} & \multicolumn{2}{|c|}{$\begin{array}{c}\text { Random CNTs in } \\
\text { matrix }\end{array}$} & \multicolumn{2}{|c|}{$\begin{array}{c}\text { Aligned CNTs in fiber } \\
\text { sizing }\end{array}$} & \multicolumn{2}{|c|}{$\begin{array}{c}\text { Random CNTs in } \\
\text { matrix }\end{array}$} \\
\hline $\mathrm{C}, * 10^{10}$ & \multicolumn{2}{|l|}{4.313} & \multicolumn{2}{|l|}{3.163} & \multicolumn{2}{|l|}{4.128} & \multicolumn{2}{|l|}{2.92} \\
\hline $\mathrm{b}$ & \multicolumn{2}{|l|}{0.382} & \multicolumn{2}{|l|}{0.433} & \multicolumn{2}{|l|}{0.415} & \multicolumn{2}{|c|}{0.504} \\
\hline
\end{tabular}

